\title{
Optimal portfolio management for individual pension plans
}

\author{
Christian Gollier ${ }^{1}$ \\ University of Toulouse (GREMAQ, IDEI)
}

November 7, 2005

\footnotetext{
${ }^{1}$ This paper benefitted from comments by two anonymous referees, and by Jacques Drèze, Thijs Knaap, Ali Lazrak, Pierre Pestieau, Eytan Sheshinsky and Richard Watt. This paper received the GSU-ARIA Award for the best paper presented at the World Risk and Insurance Conference in Salt Lake City (August 2005).
} 


\begin{abstract}
We explore the various arguments for and against the recommendation that younger households should invest a larger share of their pension wealth in risky assets. The ability of young agents to compensate their financial losses by saving more during their career provides the strongest argument in favor of younger people investing more aggressively in the stock market. Meanreversion in stock returns yields another argument. However, the uninsurability of the risky human capital goes into the opposite direction, together with the imperfect knowledge that young investors have about the distribution of asset returns.
\end{abstract}

Keywords: dynamic portfolio choice, pension plan, retirement, time horizon. 


\section{Introduction}

A large fraction of European citizens living in countries with a traditionally strong pay-as-you-go system now perceives that their social security benefits will not be sufficient to maintain their life-style after retirement. As a consequence, there is a growing demand for individual long-term savings plans that would be specifically designed for financing consumption after retirement. This phenomenon raises an interesting new decision problem for european consumers who used to save mostly for the short run. With these emerging markets, the typical time horizon for the planned consumers' investment can now be as large as 40 years. For such time horizons, the impact of the investment strategy on final wealth is enormous. Selecting this strategy is thus an important challenge for these consumers and their financial advisors.

During the XXth century in the U.S., the real return on bonds has been $1 \%$ per year, whereas investing in stocks generated an expected return of $7 \%$. Thus, a young worker investing 100 at the age of 25 would obtain a pension wealth at the age of 65 equaling 149 if she has been $100 \%$ invested in bonds. This pension wealth would equal 1497 on average if she would have invested everything in stocks. The equity premium puzzle is magnified by the exponential nature of compounded interests of long-term investors. Thus, the temptation is large for young households to take advantage of the large equity premium by investing a large fraction of their pension plan wealth on the stocks market. This is in fact one of the arguments usually presented to advocate a move from a dominant PAYG system towards a more funded system. The problem, however, is that not only the expected benefit of this strategy, but also the associated risk on the final pension wealth, are proportional to the time horizon of the investor. Investing in stocks for one year entails some risk, but investing in stocks for 40 years is 40 times riskier (if risk is measured by the variance of final wealth, assuming no serial correlation of stock returns)! Thus, it is not clear a priori that younger investors should take more risk.

The problem implicit in dynamic portfolio choices is to determine how future investment opportunities affect instantaneous investment choices. Popular treatments suggest that short time horizons often lead to excessively conservative strategies. Samuelson (1989) and several others have asked: "As you grow older and your investment horizon shortens, should you cut 
down your exposure to lucrative but risky equities?" Conventional wisdom answers affirmatively, stating that long-horizon investors can tolerate more risk because they have more time to recoup transient losses. This dictum has not received the backing of scientific theory, however. As Samuelson $(1963,1989)$ in particular points out, this "time-diversification" argument relies on a fallacious interpretation of the Law of Large Numbers: repeating an investment pattern over many periods does not cause risk to wash out in the long run. This fallacy is illustrated by the following question raised by Samuelson (1963): "I offered some lunch colleagues to bet each $\$ 200$ to $\$ 100$ that the side of a coin they specified would not appear at the first toss. One distinguished scholar (...) gave the following answer: I won't bet because I would feel the $\$ 100$ loss more than the $\$ 200$ gain. But I'll take you on if you promise to let me make 100 such bets". This story suggests that independent risks are complementary. However, Samuelson went ahead and asked why it would be optimal to accept 100 separately undesirable bets. The scholar answered: "One toss is not enough to make it reasonably sure that the law of averages will turn out in my favor. But in a hundred tosses of a coin, the law of large numbers will make it a darn good bet."

Obviously, this scholar misinterprets the Law of Large Numbers! It is not by accepting a second independent lottery that one reduces the risk associated with the first one. If $\widetilde{x}_{1}, \widetilde{x}_{2}, \ldots, \widetilde{x}_{n}$ are independent and identically distributed random wealth variables, $\widetilde{x}_{1}+\widetilde{x}_{2}+\ldots+\widetilde{x}_{n}$ has a variance $n$ times as large as the variance of each of these risks. What is stated by the Law of Large Numbers is that $\frac{1}{n} \sum_{i=1}^{n} \widetilde{x}_{i}-$ not $\sum_{i=1}^{n} \widetilde{x}_{i}$ - tends to $E \widetilde{x}_{1}$ almost surely as $n$ tends to infinity. It is by subdividing — not adding — risks that they are washed away by diversification.

Table 1 provides some information about how U.S. consumers link their optimal pension portfolio to their age. It describes actual portfolio compositions of individual TIAA-CREF plans, as observed in June 2000. A simple pattern appears in this table: consumers tend to follow the recommendation to rebalance their portfolio in favor of safer assets when growing older. Ameriks and Zeldes (2004) however show that when taking care of the time effect, there is no clear evidence supporting a gradual reduction in portfolio shares with age among TIAA-CREF participants. 


\begin{tabular}{|c|c|c|c|c|}
\hline Allocation Pattern $\backslash$ Age & Under 35 & $35-44$ & $45-54$ & Above 55 \\
\hline $100 \%$ Equity & 34.9 & 32.6 & 30.1 & 28.1 \\
\hline $75.1 \%-99.9 \%$ Equity & 17.1 & 13.8 & 10.3 & 6.6 \\
\hline $50.1 \%-75 \%$ Equity & 19.5 & 20.4 & 19.5 & 17.2 \\
\hline
\end{tabular}

Table1: Portfolio composition as a function of age.

(Sources: TIAA-CREF Institute Research (2000), and TIAA-CREF

Actuarial Technical (1986))

Following Jagannathan and Kocherlakota (1996), we show that there exist some convincing arguments sustaining the common wisdom that agents with a longer time horizon should take more risk. The next two sections present the benchmark model where an investor facing unpredictable financial markets invests at young age a specific amount to finance his consumption in $n$ years from now. We explain why the optimal portfolio is independent of $n$ in that case. In section 4 , we show that the optimal portfolio risk is increasing in $n$ if the agent can compensate early financial losses by saving more during her career. We take into account the riskiness of human capital and the flexibility of labour supply respectively in sections 5 and 6 . Section 7 is devoted to a short introduction to the effect of predictable returns (mean-reversion, stochastic volatility and Bayesian learning) on the dynamic portfolio strategy.

\section{The initial building block: Optimal static portfolios}

Let us start the analysis by assuming that the consumer is close to retire and to liquidate her portfolio. The consumer's current wealth on her individual pension account is $w_{0}$. The consumer's immediate problem is to determine the portfolio of financial assets that maximizes the expected utility of her accumulated pension wealth at the end of the period. Because of the short time remaining before the liquidation of the portfolio, this decision problem is essentially static. Assuming a complete set of Arrow-Debreu assets, this portfolio choice problem is written as

$$
\max _{c_{1}, \ldots, c_{S}} \sum_{s=1}^{S} p_{s} u\left(c_{s}\right) \quad \text { s.t. } \quad \sum_{s=1}^{S} \Pi_{s} c_{s}=w_{0},
$$


where $s=1, \ldots, S$ is an index for the $S$ possible states of nature that could prevail at the retirement date, $p_{s}$ is the objective probability of state $s, \Pi_{s}$ is the price of the Arrow-Debreu security associated to that state, and $c_{s}$ is the number of Arrow-Debreu securities $s$ that are purchased. Because $c_{s}$ is also the pension wealth of the agent at the end of the period, $u\left(c_{s}\right)$ is the utility that the retiree extracts from consuming this wealth over her remaining lifetime. We assume that $u$ is increasing and concave. The degree of tolerance to risk on retirement wealth is measured by $T(c)=-u^{\prime}(c) / u^{\prime \prime}(c)$. The budget constraint in (1) just states that the accumulated pension wealth $z$ at the beginning of the period is used to purchase portfolio $\left(c_{1}, \ldots, c_{S}\right)$ of Arrow-Debreu securities.

Observe that we do not restrict the investment opportunity set in any way. This means that households are allowed to invest in stocks, bonds, but also in real estate, portfolio insurance, options and other exotic assets. Our aim is to describe the unconstrained optimum. There are several reasons why regulators could want to restrict portfolio choices, for example because of the implicit portfolio insurance that the state would provide if a financial crash would bring future (risk-loving) retirees into poverty. Constraining individual portfolio choices may be good to fight the moral hazard problem associated with this implicit solidarity mechanism, but it introduces inefficiencies in the allocation of risk in the economy. The optimal portfolio management when upper limits to the portfolio risk are imposed is a difficult question that will not be examined in this paper. ${ }^{1}$

The first-order condition of program (1) can be written as $c_{s}=C\left(\Pi_{s} / p_{s}\right)$ where function $C$ satisfies

$$
u^{\prime}(C(\pi))=\xi \pi
$$

with $\xi$ denoting the Lagrange multiplier associated to the budget constraint. Observe that the demand for the Arrow-Debreu security $s$ is only a function of $\pi_{s}=\Pi_{s} / p_{s}$, the state price per unit of probability. Obviously, $C$ is nonincreasing in $\pi$ : risk-averse investors accept to have a smaller final wealth level in more expensive states. The riskiness of the optimal portfolio can be measured by how the riskiness of asset returns - which can be measured by the variability of $\pi_{s}=\Pi_{s} / p_{s}$ - is transferred to riskiness of final wealth. The absolute value of the derivative of $C$ with respect to $\pi$ does exactly that.

\footnotetext{
${ }^{1}$ For more details on this question, see for example Grossman and Vila (1992).
} 
Fully differentiating the condition (2) yields

$$
\left|C^{\prime}(\pi)\right|=\frac{T(C(\pi))}{\pi} .
$$

This means that more risk-tolerant agents purchase a riskier portfolio. In the remainder of the paper, we examine how the riskiness of the optimal portfolio is affected by the age of the consumer.

\section{Merton's result: Age is irrelevant}

In this section, we determine the optimal dynamic portfolio strategy of a younger consumer. This consumer with current pension wealth $w_{0}$ has $n$ periods to go before liquidating her personal pension plan. Thus, contrary to what we assumed in the previous section, she does not consume the value of the portfolio at the end of the first period. Rather, she will reinvest the accumulated capital in an asset portfolio for another $n-1$ periods. We are interested in determining how these future investment opportunities affect the attitude of the young consumer towards the current portfolio risk. To solve this problem, we use backward induction.

We assume that the investment opportunity set in each period $t$ is not contingent to the past history. The investment opportunity set at each date is thus fully characterized by the vector of Arrow-Debreu prices $\left(\Pi_{1}, \ldots, \Pi_{S}\right)$. Assuming that this vector is independent of past events means that future asset prices are unpredictable: there is no mean-reversion, no learning and no stochastic volatility in asset returns. Under this assumption, the only state variable of the dynamic problem is the accumulated wealth $z$ at the decision date under scrutiny. Given $z$ at date $t$, the consumer selects the portfolio to hold until the next date that maximizes the expected value of his pension wealth at date $t+1$ :

$$
v_{t}(z)=\max _{c_{1}, \ldots, c_{S}} \sum_{s=1}^{S} p_{s} v_{t+1}\left(c_{s}\right) \quad \text { s.t. } \quad \sum_{s=1}^{S} \Pi_{s} c_{s}=z,
$$

We first solve this problem for $t=n-1$, i.e., when the agent has only one period to go before retirement. Because $v_{n}(c)=u(c)$ by definition, this portfolio problem is formally equivalent to the static portfolio problem that we examined in the previous section. We can thus interpret $v_{n-1}(z)$ as the 
optimal expected utility of final pension wealth conditional to accumulating pension wealth $z$ one period before retirement age. Using this function, we can go one date backward to find value function $v_{n-2}$, and so on.

To determine the impact of age on the optimal portfolio, we need to compare the solutions of program (4) for the various dates $t$ from 1 to $n$. Observe that the only difference between these different programs comes from the transformation of the value function from $v_{t}$ to $v_{\tau}$. As explained in the previous section, an agent with age $t$ should accept more portfolio risk than an agent with age $\tau>t$ if and only if the value function $v_{t}$ exhibits more risk tolerance than the utility function $v_{\tau}$, or equivalently, if $-v_{t}^{\prime} / v_{t}^{\prime \prime} \geq-v_{\tau}^{\prime} / v_{\tau}^{\prime \prime}$.

Let us first compare $v_{n-1}$ to $v_{n} \equiv u$. Fully differentiating the system of equations

$$
\left\{\begin{array}{c}
p_{s} u^{\prime}\left(c_{s}\right)=\xi \Pi_{s} \\
v_{n-1}^{\prime}(z)=\xi \\
\sum_{s=1}^{S} \Pi_{s} c_{s}=z
\end{array}\right.
$$

with respect to $z$ yields

$$
T_{v_{n-1}}(z)=-\frac{v_{n-1}^{\prime}(z)}{v_{n-1}^{\prime \prime}(z)}=\sum_{s=1}^{S} \Pi_{s} T\left(c_{s}\right) .
$$

$T_{v_{n-1}}$ is the degree of tolerance to portfolio risk of the agent with two periods to go before retirement. Suppose that the agent has a power utility function $u(c)=c^{1-\gamma} /(1-\gamma)$, which implies that absolute risk tolerance $T(c)=c / \gamma$ is proportional to retirement consumption $c$. Using the budget constraint, equation (5) is then rewritten as $T_{v_{n-1}}(z)=T(z)$. By backward induction, $T_{v_{t}}(z)=T(z)$ for all $t=1, \ldots, n$ : the degrees of risk-tolerance of the value functions and of the utility function are identical. This means that the attitude towards portfolio risk is independent of age. Age, or the investment time-horizon, is irrelevant for determining the optimal structure of the pension portfolio. Here, myopia is optimal in the sense that the best investment strategy is obtained by assuming in each period that this is the last period before retirement. This result has been independently discovered by Mossin (1968), Merton (1969) and Samuelson (1969).

Proposition 1 Consider the asset allocation problem with commited and defined contributions. Assume constant relative risk aversion and unpredictable asset returns. In such a situation, the optimal portfolio structure is independent of age. 
Mossin (1968) observed that power utility functions are the only functions with such a nice property. This is easily seen from property (5) by using Jensen's inequality when $T$ is either concave or convex, or when $T(0) \neq 0$, as explained in Gollier and Zeckhauser (2002). However, calibrating the model shows that the non-proportionality of the absolute risk tolerance has only a marginal effect on the optimal portfolio of young investors.

This model relies on the assumption of frictionless financial markets. In particular, we assumed above the absence of any transaction cost and bid-ask spread. This is obviously unrealistic. Taking into account of these frictions implies that it may be optimal not to rebalance the portfolio in case of limited capital gains or losses. But their effect on the optimal portfolio at young age is ambiguous. Frictions on the housing market also have an ambiguous effect of the age structure of optimal portfolios.

\section{Human capital and flexible contributions to the pension plan}

The previous dynamic portfolio problem isolated the problem of financing consumption after retirement from the other sources of needs, incomes and risks faced by the consumer in her entire lifetime. In this section, we introduce intermediary consumption and labour incomes in the model. Suppose that the agent has $n$ consumption dates $t=1, \ldots, n$ to go before retirement. Her flow of labour incomes is denoted $\left(y_{1}, \ldots, y_{n}\right)$ and is assumed to be risk-free at this stage of the analysis. Let $\beta$ denote the psychological discount factor of the agent, and $r$ is the riskfree rate.

Consider first a pension plan in which the agent must commit herself on the flow of her contributions $\left(q_{1}, q_{2}, \ldots, q_{n}\right)$ until retirement. This is equivalent to funding the plan with a single lump-sum contribution

$$
w_{0}=\sum_{t=1}^{n} \frac{q_{t}}{(1+r)^{t}}
$$

at date $t=1$. Given that initial pension wealth $w_{0}$, the problem of the optimal dynamic portfolio management is not different to the one that we examined in the previous section. In particular, if relative risk aversion is constant, myopia is optimal: if two agents have the same current pension 
wealth $w_{0}$, they should hold the same portfolio even if they don't have the same age. The optimal portfolio risk is proportional to $T\left(w_{0}\right)$.

Consider alternatively a pension plan with fully flexible contributions over time. At each date $t$ before retirement, the agent decides how much to contribute to the plan and how to invest the pension wealth on financial markets. This dynamic consumption-portfolio problem is written as

$$
h_{t}(z)=\max _{q, c_{1}, \ldots, c_{S}} u\left(y_{t}-q\right)+\beta \sum_{s=1}^{S} p_{s} h_{t+1}\left(c_{s}\right) \quad \text { s.t. } \quad \sum_{s=1}^{S} \Pi_{s} c_{s}=z+q .
$$

From current labour income $y_{t}$ at date $t$, the agent decides to save $q$ and to consume the remaining $y_{t}-q$ at that date. Saving $q$ is added to the past accumulated wealth $z$, and everything is optimally invested on financial markets. As before, we first solve this problem for $t=n-1$, using the fact that $h_{n} \equiv u$. Solving this problem yields the optimal saving strategy $s_{0}$ and the optimal portfolio strategy $\left(c_{1}, \ldots, c_{S}\right)$ for that date. It also yields the maximum discounted expected utility $h_{n-1}$ that is used to solve the consumption-portfolio problem for date $n-2$.

Taking into account the equivalence of programs (4) and (6), we obtain that

$$
T_{h_{n-1}}(z)=T\left(c_{0}\right)+\sum_{s=1}^{S} \Pi_{s} T\left(c_{s}\right)
$$

where $c_{0}=y_{n-1}-q$ is optimal consumption. Assuming again that relative risk aversion is constant and using the budget constraint, this implies that

$$
T_{h_{n-1}}(z)=T\left(z+(1+r)^{-1} y_{n}\right),
$$

where by definition $(1+r)^{-1}=\sum \Pi_{s}$. By backward induction, we obtain that

$$
T_{h_{t}}(z)=T\left(z+Y_{t}\right) \text { where } Y_{t}=\sum_{\tau=t+1}^{n} \frac{y_{\tau}}{(1+r)^{\tau-t}}
$$

is the NPV of future labour income, i.e., the human capital at date $t$. Because $Y_{t}$ is decreasing in $t$, the degree of risk tolerance of the agent goes down when she grows older. Thus, agents with flexible contribution plans should rebalance their portfolio in favor of the risk-free asset when they are close to retire. Notice also that, because the agent starts initially with zero pension wealth $z=0$, the optimal portfolio risk at young age with this fully flexible 
pension plan is proportional to $T_{h_{0}}(0)=T\left(Y_{0}\right)$. Thus, when we allow for flexible contributions, the portfolio risk is proportional to $T\left(Y_{0}\right)$ whereas it is proportional to $T\left(w_{0}\right)=\left(w_{0} / Y_{0}\right) T\left(Y_{0}\right)$ in the rigid case. Because the NPV $w_{0}$ of the flow of contributions in the rigid plan must be smaller than the NPV $Y_{0}$ of the flow of labour incomes, we proved the following proposition.

Proposition 2 Suppose constant relative risk aversion. When the contributions to the pension plan are predetermined, the optimal portfolio risk is independent of age, whereas it is decreasing with age when contributions are flexible. Moreover, the optimal portfolio riskiness at young age is increased by a factor $Y_{0} / w_{0}$ if we allow for the contributions to the pension plan to be flexible compared to the rigid case, where $w_{0}$ is the net present value of the contributions in the rigid plan, and $Y_{0}$ is the human capital of the agent.

A crude estimate of $Y_{0} / w_{0}$ is around 10, which means that the flexible plan should invest 10 times more in risky assets than if the plan has a preestablished and rigid flow of contributions. As explained in Gollier (2002), the intuition for such a powerful effect is the ability of the flexible plan to "time-diversify" shocks on pension wealth by splitting it into small shocks on consumption over the remaining lifetime. Of course, this effect goes down as the time-horizon shortens, which yields a strong negative age effect on the optimal portfolio risk.

\section{Uncertain human capital}

Up to now, we assumed that the only source of uncertainty comes from the households' financial investments. For the sake of realism, we need to take into account the fact that the flow of labour incomes is also uncertain: young workers can face much uncertainty about the value of their human capital. In the same vein, future promotions and unemployment spells are uncertain. The uncertainty affecting human capital is expected to affect both the optimal wealth accumulation and the optimal structure of the pension portfolio. It is well-known since Leland (1968) and Drèze and Modigliani (1972) that prudent consumers will save more when their future incomes become riskier in the sense of Rothschild and Stiglitz (1970). Gollier and Pratt (1996) showed that risk-vulnerable consumers are more averse to portfolio 
risk when they bear an independent risk on their human capital. The concepts of prudence and risk vulnerability are related respectively to the third and fourth derivatives of the utility function. Consumers with constant relative risk aversion are both prudent and risk-vulnerable. Thus, under CRRA, the uncorrelated uncertainty affecting human capital raises the accumulation of financial wealth and it reduces the share of this wealth invested in risky assets.

How does the uncertainty of human capital affect the relationship between age and the optimal portfolio structure? Because younger households face more uncertainty on their human capital, they should select a safer portfolio. This argument is particularly relevant when households are likely to face a liquidity constraint. The households' unability to borrow in order to finance consumption in periods of low labour incomes magnifies the riskiness of human capital. To sum up, age horizon has two contradictory effects on the optimal portfolio. As stated in Proposition 2, younger households can better diversify their portfolio risk, which implies that they should take more portfolio risk. On the contrary, younger agents face more uncertainty on their human capital, which implies that they should select a safer portfolio. Which of these two effects dominates the other depends upon the intensity of the risk on human capital.

Including an uninsurable background risk together with a liquidity constraint to the dynamic consumption-portfolio problem makes it unsolvable analytically. In the following calibration exercise, we consider an agent with constant relative risk aversion $\gamma=10$. Both the riskfree rate and the rate of pure preference for the present are assumed to be zero. There is only one risky asset which has an excess return of $7 \%$ per year and a standard deviation of $12 \%$. We assume that the worker has 15 years to live when he retires. At the exogenous retirement age, the pension wealth is invested in the risk-free asset to finance consumption over the remaining lifetime. Before retirement, the agent faces an unemployment risk which takes the following form: when he is employed, his yearly labour income is normalized to unity, whereas unemployment benefits equal only $50 \%$ of the labour income. When employed in year $t$, the agent faces the risk to become unemployed in year $t+1$. This happens with probability $5 \%$. On the contrary, if unemployed in year $t$, the agent finds a new job in year $t+1$ with probability 0.5 . In Figure 1 , we draw the optimal investment in the risky asset as a function of financial wealth $z$, for different time horizons when the agent is employed. 


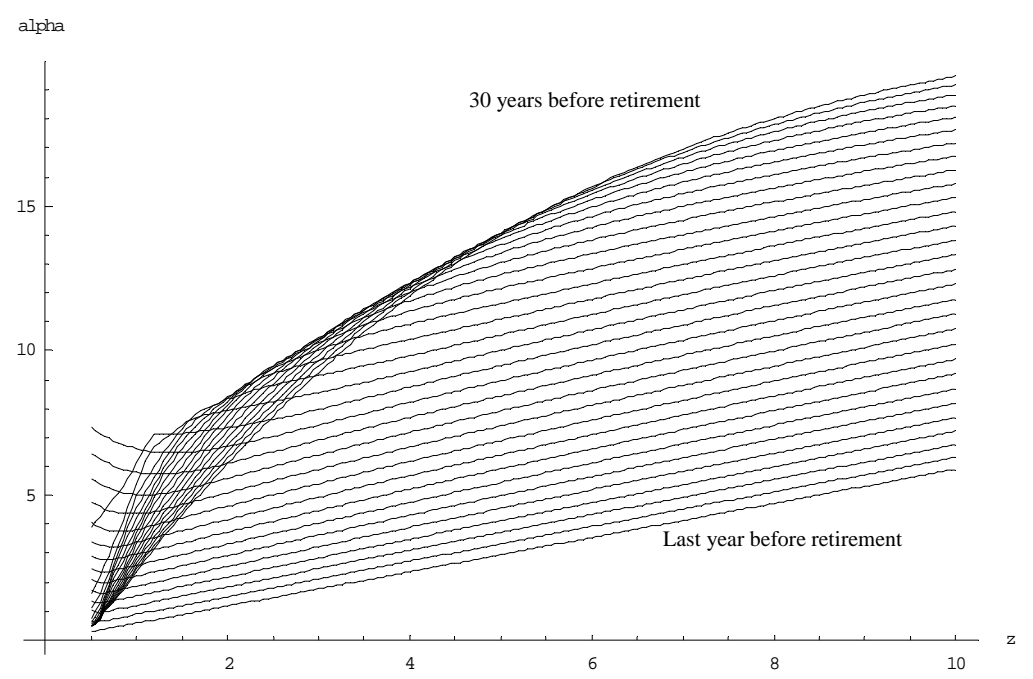

Figure 1: The optimal investment in stock (in the employment state) as a function of current financial wealth, for different time horizons.

When the agent has accumulated a large pension wealth, the riskiness of the optimal portfolio is decreasing with age, as stated in Proposition 2. But when financial reserves are small, the riskiness of the optimal portfolio is increasing with age. Because of the inability of young households to timediversify their unemployment risk, a safer portfolio is optimal. When they grow older, this risk on human capital becomes smaller, and they should rebalance their portfolio in favor of the risky asset, until the limited ability of old consumers to time-diversify their portfolio risk becomes the dominant factor. In this calibration, the effect of age on the demand for the risky asset is ceteris paribus first increasing, and then decreasing.

\section{$6 \quad$ Flexible labour supply}

Another unpleasant aspect of the benchmark dynamic model presented in section 4 comes from the assumption that households have no control of their labour supply. In particular, workers cannot compensate their financial losses on the pension wealth by working more. Bodie, Merton and Samuelson 
(1992) examined the effect of a flexible labour supply on the optimal dynamic portfolio strategy. We can extend the benchmark model (6) to endogeneize labour decision. Suppose that the agent has one unit of time per period to allocate between leisure $L$ and labour $1-L$. For the sake of simplicity, we assume that the wage per unit of working time equals $y$, which is constant over time. Let $\widehat{u}(c, L)$ denote the felicity of the agent who consumes a share $L$ of leisure and who consumes $c=y(1-L)-q$ of the consumption good, where $q$ denotes savings. As usual, we assume that $\widehat{u}$ is concave in $(c, L)$. The decision problem of the household with accumulated wealth $z$ at date $t$ can then be written as

$h_{t}(z)=\max _{L, q, c_{1}, \ldots, c_{S}} \widehat{u}(y(1-L)-q, L)+\beta \sum_{s=1}^{S} p_{s} h_{t+1}\left(c_{s}\right) \quad$ s.t. $\quad \sum_{s=1}^{S} \Pi_{s} c_{s}=z+q$.

Notice that we assume here that there is full flexibility in the sense that workers can increase or reduce their working time at any time, and at their best convenience. In particular, the agent is here assumed to fully control his/her age of retirement. It is noteworthy that the above problem is strictly equivalent to problem (6) where function $u$ would be defined as follows:

$$
u(c)=\max _{L} \widehat{u}(c-y L, L) .
$$

It is easy to check that the absolute risk aversion of the indirect utility function $u$ equals

$$
-\frac{u^{\prime \prime}(c)}{u^{\prime}(c)}=-\frac{\widehat{u}_{11}\left(c-y L^{*}, L^{*}\right)}{\widehat{u}_{1}\left(c-y L^{*}, L^{*}\right)}+\frac{\left[y \widehat{u}_{11}\left(c-y L^{*}, L^{*}\right)-\widehat{u}_{12}\left(c-y L^{*}, L^{*}\right)\right]^{2}}{y^{2} \widehat{u}_{11}\left(c-y L^{*}, L^{*}\right)-2 y \widehat{u}_{12}\left(c-y L^{*}, L^{*}\right)+\widehat{u}_{22}\left(c-y L^{*}, L^{*}\right)} .
$$

Observe that the second term of the right-hand side of the above equality is negative because of the concavity of $\widehat{u}$. Observe also that $-\widehat{u}_{11}(c-$ $\left.y L^{*}, L^{*}\right) / \widehat{u}_{1}\left(c-y L^{*}, L^{*}\right)$ is the absolute of risk aversion of a worker who rigidly supplies labour $L^{*}$. These observations yield the following proposition.

Proposition 3 Consider two agents with the same utility function $\widehat{u}$ on consumption and leisure. Let $L^{*}$ denote the optimal leisure given wage $y$ and consumption $c$. The agent who can adapt his labour supply to changes in incomes is locally less risk-averse than the agent who has a rigid labour supply 
$L^{*}:$

$$
-\frac{u^{\prime \prime}(c)}{u^{\prime}(c)} \leq-\frac{\widehat{u}_{11}\left(c-y L^{*}, L^{*}\right)}{\widehat{u}_{1}\left(c-y L^{*}, L^{*}\right)}
$$

Notice that the nature of the dynamic portfolio problem is not transformed by this form of labour flexibility. Labour flexibility just reduces the concavity of the utility function $u$ in program (6). In particular, if the indirect utility function $u$ exhibits constant relative risk aversion, the optimal portfolio structure is independent of age when contributions to the pension plan are pre-established. The only effect of the flexible labour market is to raise the share of the households' wealth invested in stocks, at all ages.

The message will not be the same if we suppose alternatively that the flexibility of labour supply is limited to the decision on the age of (partial) retirement. In that case, only the risk aversion $\left(-u^{\prime \prime} / u^{\prime}\right)$ at old age is reduced, whereas risk aversion $\left(-\widehat{u}_{11} / \widehat{u}_{1}\right)$ when retirement is not allowed remains large. This implies that the degree of risk aversion of the value function is reduced for older households, yielding a riskier optimal portfolio.

\section{Predictable asset returns}

The absence of any predictability in asset returns has long been considered as a dogma in the theory of finance. Several empirical findings have reversed this idea over the last two decades. For example, Barberis (2000) estimates significant mean-reversion in U.S. stock returns: a high return of the risky portfolio in period $t$ implies a lower expected portfolio return period $t+1$. Because mean-reversion implies that stocks are safer in the long run, the intuition suggests that a long horizon agent should have a positive "hedging demand" for risk in the initial stage of the game. Kim and Omberg (1996) and Kogan and Uppal (2000) showed that this is indeed the case if constant relative risk aversion is larger than unity. Campbell and Viceira (1999) and Barberis (2000) have shown that the hedging demand for stocks is surprisingly large. For an agent with a relative risk aversion equaling 10 and a ten-year time horizon, the optimal investment in stocks is about $40 \%$ of current wealth without predictability. It goes up to $100 \%$ when mean-reversion is taken into account.

Predictability also arises from random time-varying volatility of stock returns. There is ample evidence that large negative returns tend to be asso- 
ciated with increases in volatility over long periods of time (see for example Ghysels, Harvey and Renault (1996)). Chacko and Viceira (2000) show that long-term investors with a constant relative risk aversion larger than unity should reduce their demand for stocks in that environment.

Predictability is an important element to take into account to discuss the age profile of optimal portfolios. For investors who are close to retire, the existence of predictable future returns is irrelevant for their portfolio decision, since they will be out of the market when those changes will occur. On the contrary, households with a longer time horizon should take into account those future changes in their current choices. For example, we can infer from Barberis (2000) that the existence of mean-reversion in U.S. stocks returns multiplies the demand for stocks from investors with a ten-year time-horizon by a factor larger than 2 when compared to the stock demand from investors with only one year to go before retirement.

The predictability of asset returns is linked to changes in the investment opportunity set over time. Asset returns are somewhat predictable if these stochastic changes are correlated with an observable variable. In the cases of mean-reversion and stochastic volatility, this observable variable is the vector of past returns. More generally, when this observable variable is correlated to past returns, investors should insure against undesirable future changes in the investment opportunity set by investing more in assets which perform well when the opportunity set deteriorates. This is the hedging demand for stocks. For example, in the case of mean-reversion of stock returns, the fact that stock returns are high when the investment opportunity set deteriorates induces a positive hedging demand for stocks. On the contrary, in the case of stochastic volatility, the investment opportunity set is improved (stocks become less risky) when returns are high. This implies a negative hedging demand for stocks. This effect is small compared to the effect of mean-reversion, which implies that younger households should invest more in stocks.

In our benchmark model (4), the investment opportunity set at date $t$ is characterized by the vector $\left(\Pi_{1}, \ldots, \Pi_{S}\right)$ of the prices of the Arrow-Debreu securities. Because we assumed this vector to be stable over time, our model had no predictability in asset returns. Suppose alternatively that the vector of state prices at the beginning of the last period before retirement depends upon the state of nature $s_{n-1}$ that prevailed one period earlier. In the absence of intermediary consumption, the portfolio problem at that date can 
be written as

$$
v_{n-1}\left(z ; s_{n-1}\right)=\max _{c_{1}, \ldots, c_{S}} \sum_{s=1}^{S} p_{s} u\left(c_{s}\right) \quad \text { s.t. } \quad \sum_{s=1}^{S} \Pi_{s}\left(s_{n-1}\right) c_{s}=z .
$$

The value function $v_{n-1}$ has now a second state variable, which is past history $I$. When $u$ exhibits constant relative risk aversion $\gamma$, it is easy to check that $v_{n-1}\left(z ; s_{n-1}\right)=K_{n-1}\left(s_{n-1}\right) \frac{z^{1-\gamma}}{1-\gamma}$ with $K_{n-1}\left(s_{n-1}\right)=\left(\sum_{s=1}^{S} p_{s}\left(\frac{\Pi_{s}\left(s_{n-1}\right)}{p_{s}}\right)^{\frac{\gamma-1}{\gamma}}\right)^{\gamma}$.

Any change in history that yields a mean-preserving spread in the distribution of $\Pi / p$ makes the agent better off, i.e., raises $v_{n-1}$. Observe that this means that such a change in the investment opportunity set reduces $K_{n-1}$ if relative risk aversion is larger than unity. When $\gamma$ is less than one, a MPS in $\Pi / p$ raises $K_{n-1}$. Gollier (2004) shows that an increase in the equity premium or a reduction in the volatility of equity returns yield such a mean-preserving spread in state prices.

We are interested in determining the effect of predictability on the optimal portfolio two periods before retirement. The optimal demand for the AD security associated to state $s$ at date $t=n-2$ is determined by the marginal value of wealth in that state, which is equal to

$$
\frac{\partial v_{n-1}}{\partial z}\left(c_{s} ; s\right)=K_{n-1}(s) c_{s}^{-\gamma}=\xi_{n-2} \frac{\Pi_{s}}{p_{s}} .
$$

Suppose that the return of equity is low in state $s$, which means that $\Pi_{s} / p_{s}$ is large. First-order condition (13) implies that the demand $c_{s}$ for that $\mathrm{AD}$ security is negatively affected by this high price (negative substitution effect). But suppose that this expensive state in period $n-2$ is associated to a mean-preserving spread in state prices in period $n$, as is the case with meanreversion. When $\gamma$ is larger than unity, we know from (12) that it yields a reduction in $K_{n-1}$. This reduction yields a negative hedging demand for that AD security, thereby reinforcing the substitution effect. Symmetrically, the demand for AD securities associated to cheap states has a positive substitution effect, and a positive reinforcing hedging effect. Ex-ante, the optimal portfolio in period $n-2$ is made riskier due to the presence of mean-reversion. 
Proposition 4 Consider the dynamic investment problem with constant relative risk aversion larger than unity and with mean-reversion in equity returns. In such a situation, younger households should purchase riskier portfolios.

Observe however that this recommendation is reversed for households with a constant relative risk aversion smaller than unity. This is because mean-preserving spreads in $\Pi / p$ raise the marginal value of wealth in spite of the fact that these changes are desirable. Gollier (2004) generalizes this result to utility functions without constant relative risk aversion.

As observed by Chacko and Viceira (2000), the fact that a drop in stock returns is generally followed by an increase in stock return volatility (i.e., a mean-preserving contraction in state prices $\Pi / p)$ generates an effect on dynamic portfolio management which is exactly opposite to the one presented in Proposition 4. Contrary to mean-reversion where bad news on instantaneous returns is good news for the future investment opportunity set, stochastic volatility means that bad news on instantaneous returns is bad news for the future. Thus, stochastic volatility combined with a constant relative risk aversion larger than unity implies that younger investors should select safer portfolios.

In all these models, we assumed that investors know the distribution of stocks returns. Various authors since Detemple (1986) and Gennotte (1986) have argued that young investors may face considerable uncertainty about it. As investors grow older, they observe stock returns, and they update their beliefs by using Bayes' rule. How does this parameter uncertainty affect the optimal dynamic portfolio strategy? To answer this question, notice that good news on instantaneous returns are also good news for the future investment opportunity set, since Bayesian investors will update their beliefs in a more optimistic way after observing a large instantaneous return. Thus, as for stochastic volatility, we are in a situation opposite to the one presented in Proposition 4. As shown in Gollier (2004) who provides a complete typology of predictability models, Bayesian learning on an uncertain equity premium implies that younger investors should select safer portfolios when absolute prudence $-u^{\prime \prime \prime} / u^{\prime \prime}$ is smaller than twice the absolute risk aversion. Under constant relative risk aversion, this is equivalent to $\gamma$ being larger than unity. 


\section{Conclusion}

Should younger households invest more in risky assets? To answer this question, we first considered a simple model where households who save exclusively for their retirement do not control their contribution to their pension plan. In this benchmark model, we also assumed that assets returns are unpredictable, and that households have no flexibility in their labour supply. Following the seminal contributions of Mossin (1968), Merton (1969) and Samuelson (1969), we showed that investors with a constant relative risk aversion should select a portfolio structure which is independent of their age.

From this benchmark result, we provided two arguments in favor of a negative effect of age on the portfolio riskiness. The most convincing one relaxes the constraint that investors cannot adapt their contributions to their individual pension plan to shocks on their pension wealth. In reality, young households anticipate that they will save more during their career if their pension plans do not perform well, and that they will save less if their early portfolio return is large. This time diversification of the risk on pension wealth provides a strong incentive to invest more aggressively on the stocks market at young age. The second argument in favor of this recommendation comes from the observation that there is some mean-reversion in stocks returns. This implies that young investors face a long-term portfolio risk that is relatively smaller than in the unpredictable case. We showed that young investors with a relative risk aversion larger than unity should take into account this observation by investing more in stocks. These two effects are large. The first tends to multiply the demand for stocks from young investors by a factor 10 , whereas mean-reversion tends to multiply it by a factor 2 .

However, there also exist various arguments going in the opposite direction. First, one should take into account of the fact that the return of human capital is highly uncertain for most young households. If they cannot timediversify this risk because of liquidity constraints for example, these young households should select a safer portfolio. The fact that younger investors face some uncertainty on the true distribution of the equity premium provides another argument in favor of their selection of a safer portfolio. Finally, the fact that the volatility of equity returns is increased after a crash also tends to reduce the optimal risk exposure of long-term investors.

The fact that households can react to shocks on their pension wealth by adapting their labour supply has no clear effect on the age profile of optimal 
portfolios. If the flexibility of labour supply is the same at all ages, the only effect of this flexibility is to raise the demand for stocks at all age. On the contrary, if the labour flexibility is limited to the decision on the retirement age, then this provides an incentive for older workers to invest more in risky assets.

The bottom line of the analysis is that there is no universal answer to the question of whether younger households should be less risk-averse. Its answer depends upon individual characteristics such as for example the riskiness of the household's human capital, the intensity of potential liquidity constraints faced by it, the degree of flexibility of the household's labour supply, or the quality of the household's knowledge of the functioning of financial markets. Calibration exercises seem to favor a share of wealth invested in stocks that is decreasing with age. 


\section{References}

Ameriks, J., and S. P. Zeldes, (2004), How do household portfolio shares vary with age?, unpublished manuscript, Columbia University.

Barberis, N., (2000), Investing for the long run when returns are predictable, Journal of Finance, 55, 225-64.

Bodie, Z., R.C. Merton and W.F. Samuelson, (1992), Labor supply flexibility and portfolio choice in a life cycle model, Journal of Economic Dynamics and Control, 16, 427-449.

Campbell, J., and L. Viceira, (1999), Consumption and portfolio decisions when expected returns are time varying, Quarterly Journal of Economics, 114, 433-95.

Chacko, G., and L.M. Viceira, (2000), Dynamic consumption and portfolio choice with stochastic volatility in incomplete markets, Review of Financial Studies, forthcoming.

Detemple, J.B., (1986), Asset pricing in an economy with incomplete information, Journal of Finance, 61, 383-392.

Drèze, J.H. and F. Modigliani, (1972), Consumption decisions under uncertainty, Journal of Economic Theory, 5, 308-335.

Gennotte, G., (1986), Optimal portfolio choice under incomplete information, Journal of Finance, 41, 733-749.

Gollier, C. and J.W. Pratt, (1996), Risk vulnerability and the tempering effect of background risk, Econometrica, 64, 11091124 .

Gollier, C., (2002), Time diversification, liquidity constraints, and decreasing aversion to risk on wealth, Journal of Monetary Economics, 49, 1439-1459.

Gollier, C. and R.J. Zeckhauser, (2002), Horizon Length and Portfolio Risk, Journal of Risk and Uncertainty, 24 (3), 195212. 
Gollier, C., (2004), Optimal dynamic portfolio risk with firstorder and second-order predictability, mimeo, University of Toulouse.

Ghysels, E., A.C. Harvey, and E. Renault, (1996), Stochastic volatility, chapter 14 in G.S. Maddala and C.R. Rao (eds), Handbook of Statistics, Vol. 14, North-Holland, Amsterdam.

Jagannathan, R., and N.R. Kocherlakota, (1996), Why should older people invest less in risky assets than younger people?, Federal Reserve Bank of Minneapolis Quarterly Review, 20, 11-23. http://minneapolisfed.org/research/qr/qr2032.pdf

Kim, T.S., and E. Omberg, (1996), Dynamic nonmyopic portfolio behavior, Review of Financial Studies, 9, 141-61.

Kogan, L., and R. Uppal, (2000), Risk aversion and optimal portfolio policie in partial and general equilibrium economies, http://finance.commerce.ubc.ca/ uppal/papers.html.

Merton, R.C., (1969), Lifetime portfolio selection under uncertainty: The continuous- time case, Review of Economics and Statistics, 51, pp. 247-257.

Mossin, J., (1968), Optimal multiperiod portfolio policies, Journal of Business, 215-229.

Leland, H.E., (1968), Savings and uncertainty: The precautionary demand for savings, Quarterly Journal of Economics, 45, 621-36.

Samuelson, P.A., (1963), Risk and uncertainty: the fallacy of the Law of Large Numbers, Scientia, 98, 108-113.

Samuelson, P.A., (1969), Lifetime portfolio selection by dynamic stochastic programming, Review of Economics and Statistics, 51, 239-246.

Samuelson, P.A., (1989), The judgement of economic science on rationale portfolio management: indexing, timing, and longhorizon effects, Journal of Portfolio Management, Fall 1989, $3-12$. 
Rothschild, M. and J. Stiglitz, (1970), Increasing risk: I. A definition, Journal of Economic Theory, 2, 225-243. 